\title{
Colorectal Mucin Poor Hyperplastic Polyp
}

National Cancer Institute

\section{Source}

National Cancer Institute. Colorectal Mucin Poor Hyperplastic Polyp. NCI Thesaurus.

Code C96472.

A serrated hyperplastic polyp that arises from the colon and rectum. It is characterized by the presence of small cells in the crypts that do not contain mucin. Reactive epithelial atypia may be present. 